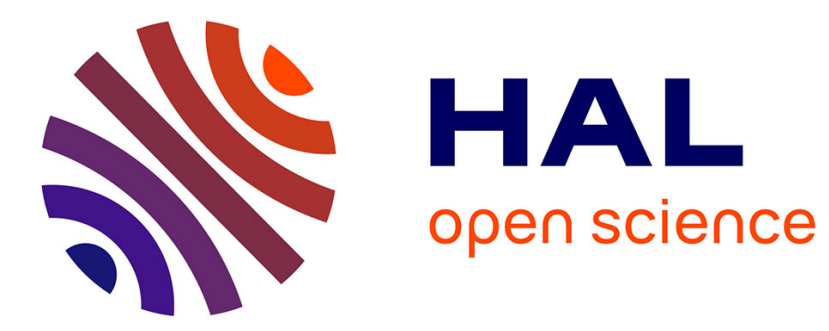

\title{
Fast fatigue life prediction of short fiber reinforced composites using a new hybrid damage approach: Application to SMC
}

\author{
M.A. Laribi, S. Tamboura, Joseph Fitoussi, A Tcharkhtchi, H. Ben Dali
}

\section{To cite this version:}

M.A. Laribi, S. Tamboura, Joseph Fitoussi, A Tcharkhtchi, H. Ben Dali. Fast fatigue life prediction of short fiber reinforced composites using a new hybrid damage approach: Application to SMC. Composites Part B: Engineering, 2018, 139, pp.155-162. 10.1016/j.compositesb.2017.11.063 . hal01826582

\section{HAL Id: hal-01826582 \\ https://hal.science/hal-01826582}

Submitted on 29 Jun 2018

HAL is a multi-disciplinary open access archive for the deposit and dissemination of scientific research documents, whether they are published or not. The documents may come from teaching and research institutions in France or abroad, or from public or private research centers.
L'archive ouverte pluridisciplinaire HAL, est destinée au dépôt et à la diffusion de documents scientifiques de niveau recherche, publiés ou non, émanant des établissements d'enseignement et de recherche français ou étrangers, des laboratoires publics ou privés. 


\title{
Fast fatigue life prediction of short fiber reinforced composites using a new hybrid damage approach: Application to SMC
}

\author{
M.A. Laribi ${ }^{\mathrm{a}, \mathrm{b}, *}$, S. Tamboura ${ }^{\mathrm{b}}$, J. Fitoussi $^{\mathrm{a}}$, R. Tié Bi ${ }^{\mathrm{c}}$, A. Tcharkhtchi ${ }^{\mathrm{a}}$, H. Ben Dali ${ }^{\mathrm{b}}$ \\ a Arts et Métiers ParisTech, PIMM - UMR CNRS 8006, 151 Boulevard de l'Hôpital, 75013 Paris, France \\ ${ }^{\mathrm{b}}$ Ecole Nationale d'Ingénieurs de Sousse, LMS, Pôle technologique, Route de Ceinture, 4054 Sousse, Tunisia \\ ${ }^{\mathrm{c}}$ Automotive Exteriors Europe, 18 bis rue de Verdun BP 15178, 25402 Audincourt, France
}

\section{A R T I C L E I N F O}

\section{Keywords:}

Fiber reinforced composite

Damage-mechanics

Micro-mechanics

Fatigue life prediction

\begin{abstract}
A B S T R A C T
Industrial design of Short Fiber Reinforced Composites (SFRC) structures is subject to several compounding and processing steps of optimization. Moreover, these structures are often submitted to fatigue loading. Therefore, SN curves have to be established for each new composite formulation and for several type of microstructure involved in the real component due to processing. While these preliminary characterizations are time and money consuming, this paper propose a new hybrid methodology for fast fatigue life prediction. Moreover, both monotonic and fatigue behavior of SMC composites is essentially determined by local damage propagation. Therefore, the key idea of the proposed approach is to use a Mori and Tanaka based micromechanical model in order to establish an equation of state relating local damage rate to macroscopic residual stiffness rate. The generalization of this relation to fatigue damage multi-scale description leads to the SN curve fast determination of each considered microstructure. Very limited experimental characterization is required in such a way that SN curve could be established in just one day. Comparison between experimental and simulated Whöler curves highlights a very good agreement for several microstructure configurations in the case of a SMC composite material.
\end{abstract}

\section{Introduction}

For an efficient design of short fiber reinforced composites SFRC automotive components, several modes of failure have to be taken into account by the manufacturers. Particularly, fatigue loading may be considered as one of the most critical failure mode which strongly affects the component lifetime. In fact, poor knowledge and control of this mode of failure lead to specifications provided by the manufacturers which often need to be clarified. Moreover, the existent experimental databases, which should allow at least a pre-design, remain relatively poor especially for new material formulations. On the other hand, the development times become increasingly short and must also integrate the material formulation optimization. Several iterations are often necessary in order to identify the correct couple formulationprocess suitable for each new application. Thus, it seems essential to build a rapid methodology of pre-dimensioning of composite structures allowing, within a short time, to identify the appropriate material formulation for each new automotive SFRC component. This methodology must therefore be pragmatic for industrial purpose. In the case of components submitted to fatigue loading, this is a critical issue because of the too long and too costly experimental campaigns needed to established SN curves.

Moreover, because of their heterogeneous architecture, anisotropic behavior and damage development, short fiber reinforcement composites SFRC structure design is very complex compared to homogeneous materials such as metals. Indeed, the mechanical properties of these materials were found to be greatly affected by their composition [1]: matrix type (thermoplastic or thermoset), volume fraction of reinforcing phase and their geometry and spatial distribution [2-5]. The diversity of composite material architectures and their complexity has for each application its own specificity. This wide variety of microstructures induces a significant dispersion of the mechanical properties, in particular under fatigue loading where the prediction of thresholds and kinetics of damage, their effect on the residual mechanical behavior and on the lifetime of the materials can present a very important challenge. These scattered results on composite S-N curves have been demonstrated by Barnard and al [6]. The authors admit the change of the damage mechanism as a result of microstructure variation and damage during the different stages of the fatigue process. They have also shown that there is a direct relationship between the strength statistical 
variation and the scatter observed in the composite S-N curves. One can expect that in the case of SFRC materials, this effect should be largely exacerbated because of the high variability of the microstructure generated during their molding process [7]. In fact, even for a single formulation, numerous different microstructures are present in a real SFRC automotive component. Consequently, a predictive modeling must imperatively integrate the microstructure as an input data.

Therefore, considering the complexity of the local mechanisms occurring during loading, the chosen approach must be based on a solid knowledge of these different phenomena. In the case of short fiber reinforced composites such as Sheet Molding Compound, it has been widely demonstrated that local damage must be a central focus of the design methodology $[1,8]$. Unlike thermoplastic based SFRC, non-linear behavior due to matrix visco-plasticity does not have to be taken into account at ambient temperature and low frequency.

However, in the case of fatigue behavior, environmental and loading conditions effects (temperature [9], stress ratio [10,11], cycling frequency $[12,13]$ ) are considered to be of first importance. Thus, the chosen methodology should be able to be adapted to predict the lifetime of these materials under these various complex conditions. On the other hand, fatigue damage and failure behavior of SFRC materials appears to be a very complicated and various process. Mainly, the existing predictive fatigue models for SFRC are generally classified into three categories [1,14]; empirical, based on S-N curves; phenomenological, based on residual strength or on residual stiffness evolutions and finally micromechanical, based on microscopic damage mechanisms description.

Great efforts have been expended to develop new methods allowing reducing substantially cost and time dedicated to characterization of fatigue behavior [15-21]. L. Jegou and al. proposed a new approach [17] based on the temperature measurements. An energetic fatigue criteria, identified from measurement results, is obtained from only one single microstructure in order to predict the fatigue curve from the heat build-up curve. The duration of the whole procedure is less than two days. Yann Marco and al [18] proposed in another recent paper a similar approach by relating the fatigue lifetime to the crack population evaluated from interrupted fatigue tests and the energy dissipation for a Natural Rubber compound filled with carbon black. This approach [17-21] proposes an efficient Wohler curves prediction based only on thermal measurements and an energetic criterion and has been applied on a wide variety of thermoplastic polymers and rubbers [21]. However, the authors do not specify if this approach should be effective in the case of thermoset polymer or their composites presenting a lower thermal effect especially with low operating frequency and amplitude [22].

Jain and al $[23,24]$ have proposed an approach based on a micromechanical model relating the macroscopic damage state in quasi-static loading to that reached as a certain point on a givenS-N curve. The authors propose a methodology allowing prediction of the S-N curves for other composites microstructures from the knowledge of the so called "master curve" which corresponds to the S-N curve established for one specific microstructure taken as a reference. However, the proposed methodology is based on the experimental statement that for similar number of cycles to failure, the difference in the loss of stiffness curves for different microstructures is not significant and can be statistically treated as being the same. Experimental evidence shows that, in the case of SMC materials, the loss of stiffness kinetic and its critical value just before failure is strongly dependent of the microstructure.

In this paper, a hybrid modeling approach is proposed. In order to take into account microstructure and damage effect, this model is based on a Mori and Tanaka predictive approach integrating a damage criterion at the microstructure scale. This model is identified in the case of a simple tensile loading for one single microstructure and is able to predict the monotonic mechanical response for each other microstructure. Then, using the output of this micromechanical model, a phenomenological formulation allows a rapid evaluation of the $\mathrm{SN}$ curve for different other microstructures. In order to drive the model, limited experimental data from laboratory tests are needed.

In the next section, the different steps of the proposed methodology are presented. Then, the micromechanical damage model is described until the identification of an equation of state applicable under monotonic tensile loading. The model is applied to a SMC composite material which is presented together with the experimental methods and results in the third section. The last section is dedicated to write an equation of state under fatigue loading to be solved in order to establish SN curves with minimum experimental data. The methodology is validated for three kinds of microstructure: a Randomly Oriented SMC (RO) and a Highly Oriented SMC under two fatigue loading directions (HO- $0^{\circ}$ and HO- $90^{\circ}$ ).

\section{Presentation of the new hybrid methodology}

In this study, we are looking for a pragmatic methodology of rapid design of SFRC materials submitted to fatigue loading. This approach is suitable for thermoset based composite materials such as SMC composites for which non-linear behavior is essentially attributed to damage phenomenon. Therefore, this is a stiffness based model based on a micromechanical approach in which a damage criterion in introduced at the local scale. This model is presented in the next section. Further development of our approach will be proposed in the case of thermoplastic based composites for which matrix non-linearity should be taken into account.

The key idea of this approach is to introduce the output of an accurate micromechanical damage model into a phenomenological approach. Such a hybrid model combines the advantages of both micromechanical and phenomenological approaches: In one hand, the proposed methodology is pragmatic and well adapted to industrial design. On the other hand, our model keeps the reliability of the micromechanical approach through the description of local damage evolution. As it has been shown in previous studies [25,26], the non-linear behavior of standard SMCs submitted to quasi-static, dynamic or fatigue loading is mainly governed by the same phenomenology: fibre-matrix interface failure development. Under tensile or fatigue loading, accumulation and propagation of local damage lead to a progressive loss of stiffness which can be considered as a good indicator of damage state. Therefore, independently of the loading type, any local damage state can be directly related to the corresponding degraded macroscopic properties. In other words, the relation between local damage and macroscopic loss of stiffness should be understood as an intrinsic relationship. Consequently, it is obvious to consider that fatigue damage and tensile damage can be described by the same type of relationship.

Previous experimental studies [25-28] showed that final failure appears when the micro-cracks density reaches a certain critical value. This critical value can be represented as a local damage rate, $\frac{d}{d_{c}}$ where $\mathrm{d}$ is related to the current amount of fibre-matrix interface damage and $\mathrm{d}_{\mathrm{c}}$ is a critical value. In SMC composite materials, one can assume that the pseudo-delamination phenomenon which always appears just before failure $[29,30]$, takes place when the local damage rate is equal to 1. Therefore, one can consider the local failure criterion as:

$\frac{\mathrm{d}}{\mathrm{d}_{\mathrm{c}}}=1$

In the proposed fatigue life prediction model, this criterion is supposed to be an intrinsic characteristic of the material independently of the applied loading type: quasi-static or fatigue. Physically, it means that failure always occurs for the same critical amount of local damage independently of the loading history when the non-damage volume of the material becomes too small to withstand the applied load. Consequently, when the critical local damage rate is reached, coalescence of micro-cracks rapidly leads to final failure. Therefore, one can consider that the failure criterion described in equation (1) can be 
identified using quasi-static response and then be used for the prediction of fatigue degradation and failure. It is then obvious to consider that fatigue life prediction model for elastic damageable composites should be based on a quasi-static loading micromechanical approach taking into account microstructure and damage phenomenon at the local scales. The same idea is used in recent publications and applied to thermoset matrix composites [23,24].

Continuous efforts have been dedicated in the last two decades to the experimental analysis and the multi-scale modeling of SMC composites submitted to quasi-static, high strain rate and fatigue behavior $[23,25,31,32]$. Thus, the present approach is based on the use of an existing micromechanical model predicting quasi-static and dynamic behavior of SMC composite [27]. In this model, a fibre-matrix interface failure is introduced in the Mori and Tanaka approach [33]. Micromechanical parameters describing fibre-matrix interface failure development and the critical local damage value $\left(\mathrm{d}_{\mathrm{c}}\right)$ can be identified by inverse engineering using tensile and loading-unloading tensile test results (see section 5).

Therefore, the local damage rate evolution can be determined and related to the macroscopic loss of stiffness in the case of a simple tensile loading. The relation between the local damage rate and the macroscopic loss of stiffness derived from the micromechanical damage modeling of this simple tensile test can be considered as an equation of state which can be then adapted and used as an intrinsic relationship for fatigue life prediction. The introduction of this equation of state into a stiffness based fatigue phenomenological formulation leads to the expression of the evolution of the local damage rate during fatigue loading. Finally, the failure criterion expressed in equation (1) allows predicting S-N curves of SMC materials for different microstructures. The whole methodology is represented schematically in Fig. 1.

One can summarize the rapid evaluation of the Wöhler curve by the four following stages:

1) Performing tensile and loading-unloading tests in order to determine the damage threshold $\sigma^{s}$ and the loss of stiffness kinetics under monotonic tensile loading represented by the parameter a (see section 5).

2) Performing tension-tension fatigue tests without the necessity to reach the failure in order to identify the kinetics of reduction in stiffness in fatigue loading represented by the parameter B (see section 6).

3) Identification of the micromechanical model for monotonic loading in order to determine the tensile equation of state,

4) Introduction of the identified loss of stiffness kinetics into the equation of state and resolution in order to plot the Wohler curves (cf. equation (14)).

This procedure can be used for each new microstructure in order to obtain a rapid evaluation of the corresponding Whöler curve.

\section{Material and experimental methods}

Our methodology is applied to an industrial SMC material. Hereafter are described material and experimental methods.

\subsection{Material}

The material in study is polyester based Sheet Molding Compound composite (SMC). Glass fibers and $\mathrm{CaCO} 3$ particles weight contents are of $28 \%$ and $37 \%$ respectively are introduced in the formulation.

Glass fibers are presented in the form of bundles, with constant length $\mathrm{L}=25 \mathrm{~mm}$. Each bundle contains approximately 250 glass fibers of $15 \mu \mathrm{m}$ diameter. Bundles are originally randomly oriented in the plane of the non-reticulated SMC flanks to be processed by thermocompression.

SMC plates are obtained by thermo-compression under a pressure of $60 \mathrm{Bars}$ and an average temperature of $165^{\circ} \mathrm{C}$ of the mold. Reticulation time is less than two minutes. Two molding configurations have been used. In the first one, non-reticulated SMC flanks have been placed in the center of the rectangular mold $\left(120 \times 250 \mathrm{~mm}^{2}\right)$ and recover more than $80 \%$ of its surface. Consequently, limited flowing during compression molding leads to a quit random orientation of the fibers (RO material). On the other hand, the same amount of SMC flanks has been placed in one edge of the mold in such a way that only $50 \%$ of the mold was recovered. This leads to a highly oriented distribution of fibers in the flow direction (HO material).

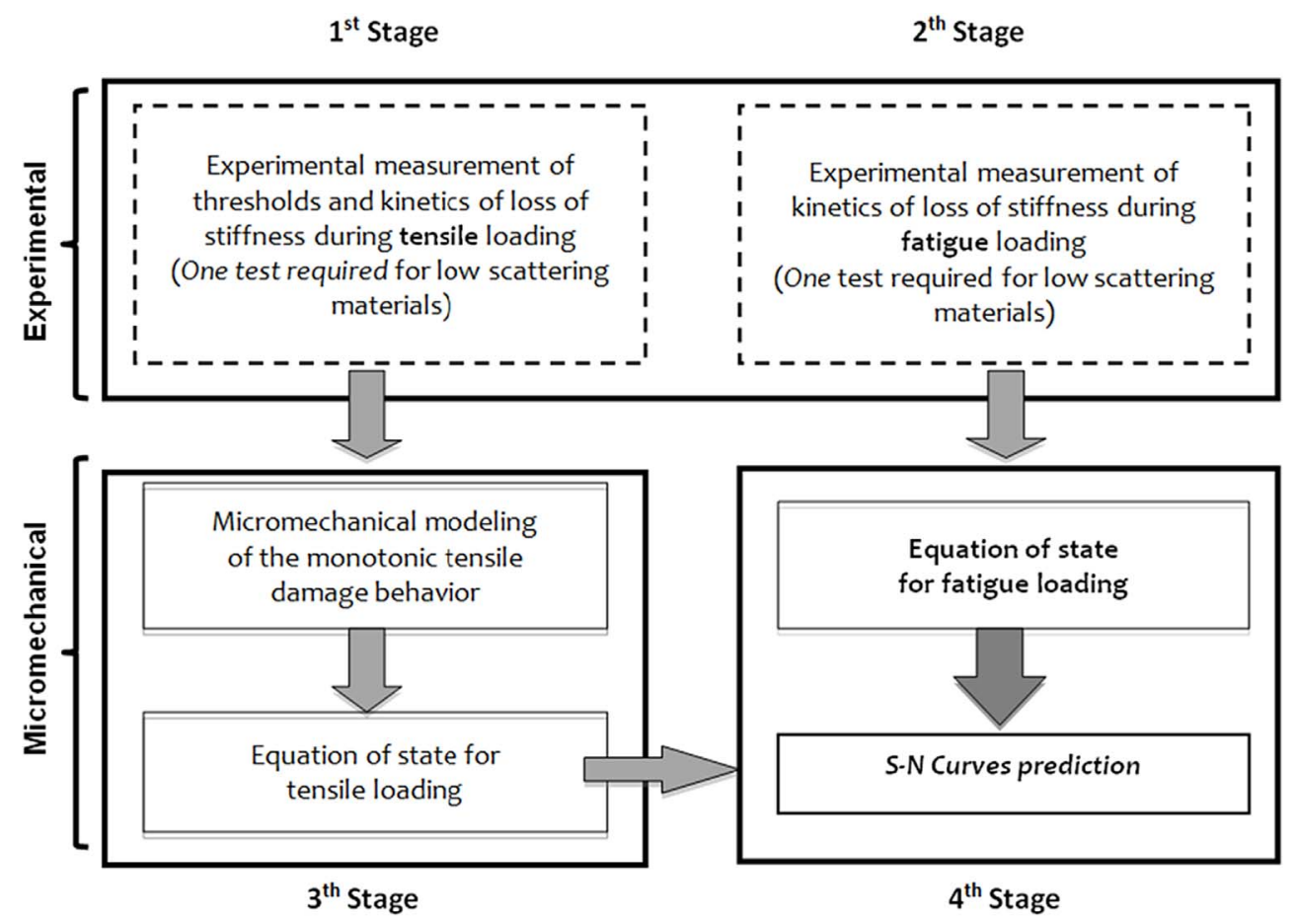

Fig. 1. Representation of the proposed methodology. 


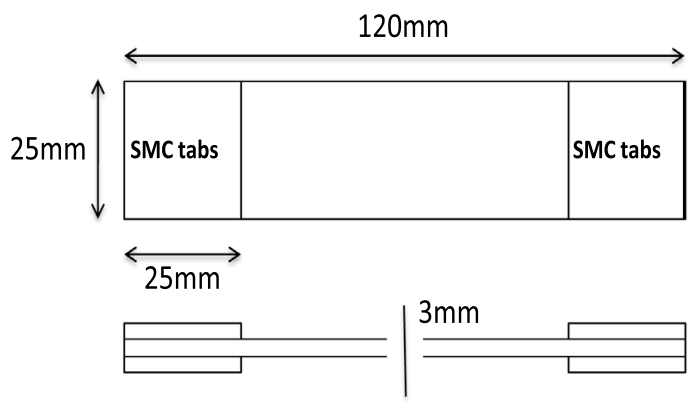

Fig. 2. SMC specimen geometry used for tensile and fatigue tests.

\subsection{Mechanical characterization methods}

Overall mechanical characterizations of the SMC (quasi-static and fatigue) behavior have been performed on a MTS 830 hydraulic machine.

\subsubsection{Specimen geometry}

Tensile and fatigue specimens were cut from RO and HO plates. Fig. 2 shows the used specimen geometry.

In the case of $\mathrm{HO}$ microstructure, two specimen orientations were chosen. HO- $0^{\circ}$ and $\mathrm{HO}-90^{\circ}$ denote specimens cut in the flow direction and perpendicularly to it respectively.

\subsubsection{Test configurations}

Three test configurations have been used:

- Tensile tests until failure (in the two main directions for the oriented material). Thus, average final failure stresses are provided for the three test configurations: RO, $\mathrm{HO}-0^{\circ}$ and $\mathrm{HO}-90^{\circ}$.

- Loading-unloading tensile tests with progressive increase of the maximum load. The main aim of these tests was to plot the relative loss of stiffness evolution $\left(\frac{\mathrm{E}}{\mathrm{E}_{0}}\right)$ versus the applied stress.

- Tension-tension stress controlled fatigue tests until failure at several applied maximum stress. The chosen stress-ratio and frequency were $\mathrm{R}=0.1$ and $\mathrm{f}=10 \mathrm{~Hz}$. All fatigue tests were preceded by a tensile loading-unloading-elastic reloading cycle allowing a better identification of the non-damaged material Young's modulus, $E_{0}$ and $E_{1}$, corresponding to the residual stiffness after the first cycle. The relative loss of stiffness evolution during fatigue is determined and Whöler curves are plotted for each microstructure configuration. Note that the systems cannot reach the requested cycling immediately at the first applied cycle. For an applied frequency of $10 \mathrm{~Hz}$, it takes generally $\mathrm{N}_{\mathrm{s}}$ cycles to reach the goal (around 20 cycles in our case). So, it is considered that the required experimental conditions are properly applied only from the $\mathrm{N}_{\mathrm{s}}$ cycle. We verify for all performed fatigue tests that no evolution of the relative loss of stiffness is observed until cycle $\mathrm{N}_{\mathrm{s}}$. Thus, one can assume that $\frac{\mathrm{E}_{\mathrm{N}_{\mathrm{S}}}}{\mathrm{E}_{0}}=\frac{\mathrm{E}_{1}}{\mathrm{E}_{0}}$

\section{Micromechanical model}

\subsection{Micromechanical damage modeling}

The micromechanical multi-scale modeling proposed here is derived from the Jendli \& al. work [25]. This predictive modeling involves the introduction of local damage into standard homogenization technique. The latter allows predicting the overall behavior of heterogeneous materials from their constituent's properties. The damage model considered in this study is based on the theory proposed by Mori and Tanaka [33] and adapted by Benveniste [34]. Mori and Tanaka's theory gives access to the whole elasticity tensor of the composite as a function of microstructure parameters such as the fiber content, distribution of orientation and length of fibers. Composite stiffness tensor is given by the expression:

$C^{\text {Comp }}=C^{m}\left[I+f\langle Q\rangle(I+f\langle(S-I) Q\rangle)^{-1}\right]^{-1}$

where $C^{m}$ and $C^{i}$ are the stiffness tensor of the matrix and the reinforcement respectively, $f$ represents the reinforcement volume fraction and $Q$ is a pseudo-localization tensor defined for each family of reinforcement "i" as:

$\mathrm{Q}^{\mathrm{i}}=\left(\left(\mathrm{C}^{\mathrm{m}}-\mathrm{C}^{\mathrm{i}}\right)\left(\mathrm{S}^{\mathrm{i}}-\mathrm{I}\right)-\mathrm{C}^{\mathrm{i}}\right)^{-1}\left(\mathrm{C}^{\mathrm{i}}-\mathrm{C}^{\mathrm{m}}\right)$

This expression integrates the Eshelby tensor $\boldsymbol{S}$ [35].

Moreover, for a given macroscopic applied stress $\sum$, average stress and strain fields in each phase of the material (matrix or fiber) can be determined. Several criteria of local damage can then be introduced and put in competition at the local scale. Because fiber-matrix interface debonding is the predominant damage mechanism occurring in SMC composites, local stresses on the interface must be calculated. For a given macroscopic applied stress $\sum$, Mori and Tanaka theory gives access to the average stress tensor for each family of fibers oriented in the "i" direction as:

$\sigma^{\mathrm{i}}=\mathrm{C}^{\mathrm{m}}\left(\mathrm{I}+\left(\mathrm{S}^{\mathrm{i}}-\mathrm{I}\right) \mathrm{Q}^{\mathrm{i}}\right)(\mathrm{I}+\langle\mathrm{f}(\mathrm{S}-\mathrm{I}) \mathrm{Q}\rangle) \mathrm{C}^{\mathrm{m}-1} \sum$

Using the continuity condition of the normal stress at the interface, the average stress in the fiber given by equation (4) is used to calculate the normal and shear interfacial stresses, $\sigma_{n}$ and $\tau$ respectively, at each point located at the fiber-matrix interface:

$\sigma_{\mathrm{n}}=\overrightarrow{\mathrm{T}} \cdot \overrightarrow{\mathrm{n}}$

with $\overrightarrow{\mathrm{T}}=\sigma^{\mathrm{i}} \cdot \overrightarrow{\mathrm{n}}$ and $\tau^{\mathrm{i}}=\sqrt{\overrightarrow{\mathrm{T}}-\left(\sigma_{\mathrm{n}}\right)^{2}}$

where $\vec{n}$ is the normal vector at the considered point of the interface see Fig. 3 (a).

Fitoussi \& al [36] propose the introduction of a statistical local interface failure criterion in order to predict threshold and kinetic of damage at the local scale. Jendli \& al [27] generalized this approach for dynamic loading. At each calculation step, a local failure probability is calculated at each point located on the fiber-matrix interface and defined by two angles, $\theta$ and $\phi$. The first one is related to the in-plane orientation of the considered fiber and $\phi$ defines the position of the
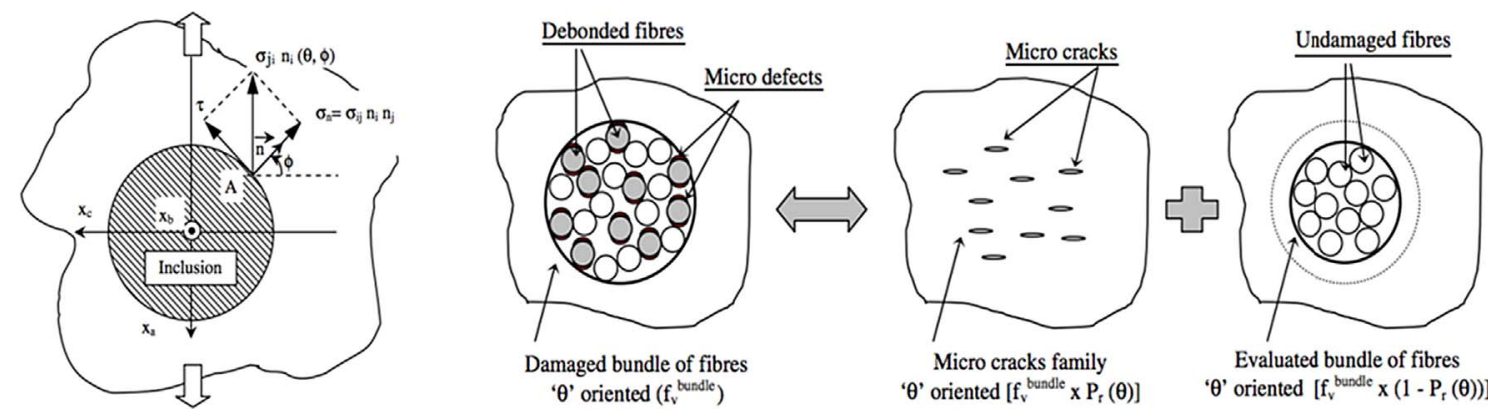

Fig. 3. (a) Projection of the stress tensor (normal and shear interface stresses, $\sigma$ and $\tau$ respectively). (b) Micromechanical damage description. (From Jendli \& al. [27]). 
interfacial point around the fiber equator. The probability function is written according to Weibull law [28]:

$\mathrm{P}_{\mathrm{r}}(\theta, \varphi)=1-\exp \left(-\left(\left(\frac{\sigma}{\sigma_{0}}\right)^{2}+\left(\frac{\tau}{\tau_{0}}\right)^{2}\right)^{\mathrm{m}}\right)$

where $\tau$ and $\sigma$ are the shear and normal stresses derived from equation (5). $\sigma_{0}$ and $\tau_{0}$ are interfacial strengths under normal and shear stress at the interface respectively. " $\mathrm{m}$ " is a statistical parameter directly function of the local distribution of microstructure.

Local damage is introduced in the composite material through a density of zero stiffness penny shape heterogeneities describing the presence of the micro cracks coming from the interfacial damage. A damaged state should be described by micro-cracks and fibers. Two kinds active fibers participating in the composite reinforcement should be distinguished: the non-debonded fibers and the part of the debonded fibers which remain active (see Fig. 3 (b)).

Therefore, at each calculation step, $n$, local interface failure probabilities are calculated and gives access to the amounts of remaining active fiber, $\mathrm{f}_{\mathrm{n}}^{\text {act }}$, including the undamaged fibers volume fraction, $\mathrm{f}_{\mathrm{n}}^{\mathrm{ND}}$, the part of the debonded fiber which continue participating in the composite reinforcement, and the micro-cracks volume fraction to be introduced. Therefore, the local damage state is described at each step, $\mathrm{n}$, by the following equations:

$\mathrm{f}_{\mathrm{n}}^{\mathrm{ND}}=\left(1-\mathrm{P}_{\mathrm{r}}^{\mathrm{n}}\right) * \mathrm{f}_{\mathrm{n}-1}^{\mathrm{ND}}$

$\mathrm{f}_{\mathrm{n}}^{\mathrm{act}}=\mathrm{f}_{\mathrm{n}}^{\mathrm{ND}}+\mathrm{k} \sum_{\mathrm{i}=1}^{\mathrm{n}} \mathrm{P}_{\mathrm{r}}^{\mathrm{i}} \cdot \mathrm{f}_{\mathrm{i}-1}^{\mathrm{ND}}$

$\mathrm{f}_{\mathrm{n}}^{\mathrm{mc}}=\mathrm{f}_{\mathrm{n}-1}^{\mathrm{mc}}+h \cdot \mathrm{P}_{\mathrm{r}}^{\mathrm{n}} \cdot \mathrm{f}_{\mathrm{n}-1}^{\mathrm{ND}}$

where $\mathbf{k}$ is a reduction coefficient applied to partially debonded fibers. This parameter has been evaluated by finite element calculations performed on a representative cell containing a partially debonded fiber and is equal to $0,5 . \mathbf{h}$ is the ratio between the volume of the introduced penny shape (representing interfacial micro-crack) and the fiber evaluated by geometric considerations.

Therefore, the homogenization of the composite material containing remaining active fibre, matrix and micro-cracks can be achieved according to a two successive stages as described in Jendli \& al. paper [27].

\section{Experimental results and micromechanical model identification}

\subsection{Loss of stiffness during tensile loading}

Tensile loss of stiffness is measured by the loading-unloading procedure described in section 3.2.2. The micromechanical model described above allows predicting the evolution of the properties of the equivalent homogeneous material. As a result, one can easily plot the evolution of the progressive reduction of stiffness during a tensile loading. The key issue of the micromechanical model lies in the identification of the local fiber-matrix interface failure criterion parameters. The latter is identified by reverse engineering on the basis of the reduction in stiffness measured in the testing microstructure. The identification procedure is described in Ref. [27]. Comparison between model and experimental data is shown in Fig. 4.

For the sake of simplification, the average evolution of the relative loss of stiffness should be considered. In a first approach, a linear function can be chosen to represent the average evolution of the relative loss of stiffness. This linear function is defined in the range of stress values corresponding to the evaluated acceptable fatigue applied stresses in real structures.

Thus, relative loss of stiffness during a tensile loading can be expressed by:

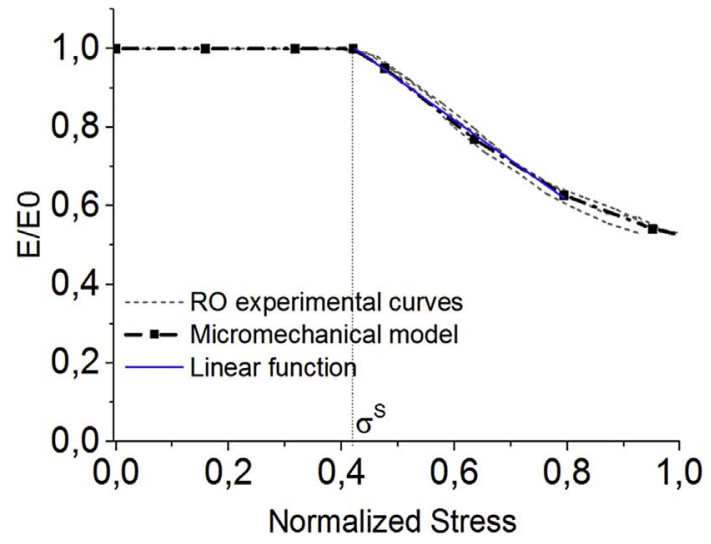

Fig. 4. Evolution of the relative loss of stiffness during tensile loading.

$\left(\frac{E}{E_{0}}\right)=1+a\left(\sigma-\sigma^{S}\right)$.

where $\sigma^{S}$ is the average damage threshold stress, a is a kinetic parameter and $\sigma$ is the applied stress. Therefore, when considering another microstructure.

\subsection{Determination of an accurate local damage indicator}

The hybrid approach proposed in this paper relies on the definition of a local damage indicator and its critical value corresponding to a critical damage state leading to failure. Thus, the definition of the local damage indicator, $\mathrm{d}$, and its associated critical value, $\mathrm{d}_{\mathrm{c}}$, should be related to the local parameters describing the local damage state; namely, the micro-crack density $\mathrm{f}_{\mathrm{n}}^{\mathrm{mc}}$, and the remaining active fibers, $\mathrm{f}_{\mathrm{n}}^{\text {act }}$ which are the output of the micromechanical modeling.

The chosen indicator is:

$\mathrm{d}=\mathrm{f}^{\mathrm{mc}} \mathrm{f}^{\text {act }}$

Final failure stress is needed to identify, through a reverse engineering method, the critical value of the local damage rate, $d_{c}$. Indeed, the micromechanical model allows plotting the evolution of the local damage amount, $d$, until the measured failure stress for the considered microstructure. The corresponding value to failure is equal to $d_{c}$. For the sake of confidentiality normalized average failure stress values is defined by the ratio between the failure stress and the average failure stress of RO samples, Thus, the normalized average failure stress of RO, HO- $90^{\circ}$ and HO- $0^{\circ}$ samples are $1( \pm 0,074), 0,83( \pm 0,076)$ and $1,69( \pm 0,15)$. It is obvious to note that for the three studied microstructure (RO, $\mathrm{HO}-0^{\circ}$ and $\left.\mathrm{HO}-90^{\circ}\right)$ identified values of $\mathrm{d}_{\mathrm{c}}$ are of the same order of magnitude. This indicates that the critical local configuration leading to the final failure is independent of the microstructure.

\subsection{Equation of state under tensile loading}

The micromechanical model allows plotting the evolution of the local damage rate, $\frac{d}{d_{c}}$ as a function of the stiffness reduction, $\frac{E}{E_{0}}$ (see Fig. 5). As we mentioned above, this relation is considered as an equation of state relating microscopic damage state to macroscopic properties degradation. Therefore, this relationship is supposed to be accurate even for other loading scheme such as fatigue.

It is easy to describe the equation of state as a polynomial function of the second degree:

$\frac{d}{d_{c}}=\alpha_{i}\left[\left(\frac{E}{E_{0}}\right)\right]^{2}+\beta_{i}\left[\left(\frac{E}{E_{0}}\right)\right]+\gamma_{i}$

$\alpha, \beta$ and $\gamma$ are micromechanical parameters, " $i$ " index indicates the considered microstructure, (RO, $\mathrm{HO}-0^{\circ}$ and $\mathrm{H} 0-90^{\circ}$ ). 


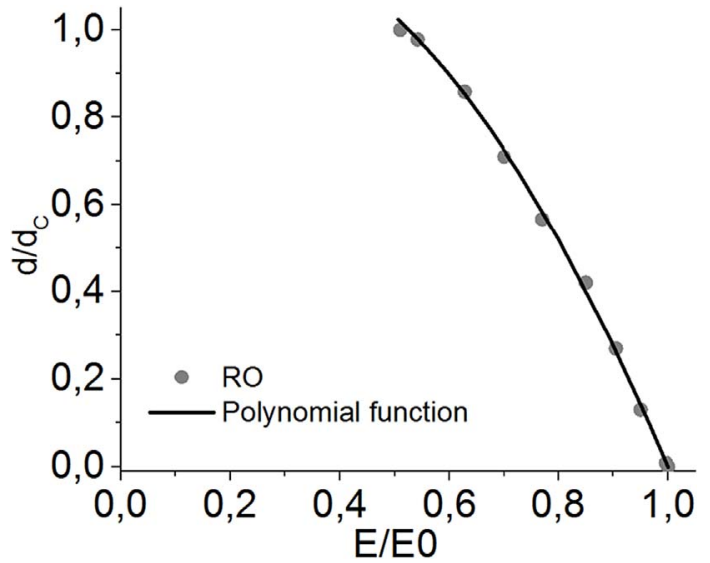

Fig. 5. Evolution of the local damage rate in function of the loss in stiffness.

\section{Hybrid model and fatigue life prediction}

In order to emphasize the degradation kinetic, it is interesting to plot the evolution of the relative loss of stiffness $\frac{E}{E_{1}}$, where $E$ is the residual stiffness for the current cycle and $E_{1}$ is the residual stiffness after the first cycle. Comparison between relative loss of stiffness $\frac{E}{E_{1}}$, plotted for different values of applied fatigue stress highlights an average damage kinetic which can be described by the following power function:

$$
\left(\frac{\mathrm{E}}{\mathrm{E}_{1}}\right)_{\mathrm{N}}=\mathrm{AN}^{\mathrm{B}}
$$

One can notice that, in the case of a SMC composite material, the variation of the slope around the average kinetic does not depend on the applied stress level. This experimental evidence has been also confirmed in the case of other microstructure configurations such as $\mathrm{HO}-0^{\circ}$ and $\mathrm{HO}-90^{\circ}$. The scatter observed on the damage kinetic and on the fatigue life time is essentially due to the dispersion of microstructure which has been demonstrated to be very variable in the case of SMC composites. Like in tension loading, this topic is not addressed and will be the subject of a further paper.

In Fig. 6, all the curves are plotted from the $\mathrm{N}_{\mathrm{s}}$ cycle which should be considered equivalent to the first cycle as mentioned above.

Besides, relative loss of stiffness during fatigue loading can be decomposed into two terms:

$\left(\frac{E}{E_{0}}\right)=\left(\frac{E}{E_{1}}\right) *\left(\frac{E_{1}}{E_{0}}\right)$

The first term, $\frac{\mathrm{E}}{\mathrm{E}_{1}}$ defines the fatigue loss of stiffness rate described

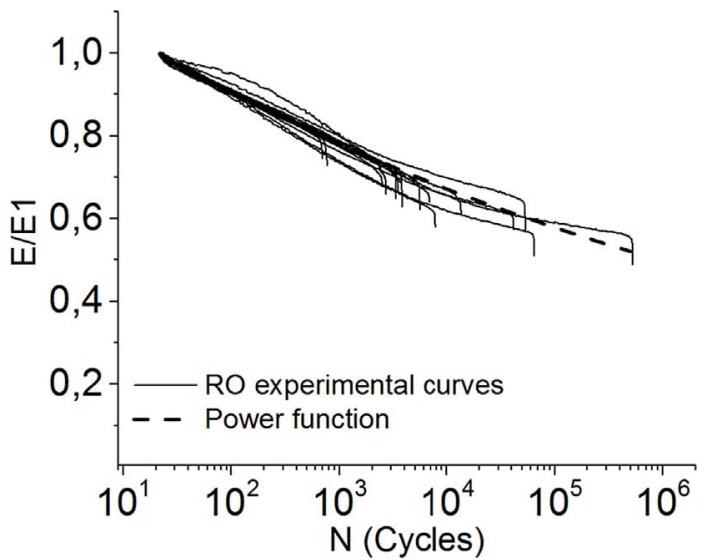

Fig. 6. Loss of stiffness in fatigue for a RO material for different applied stress level. by the parameter $\mathrm{B}$ whereas $\frac{\mathrm{E}_{1}}{\mathrm{E}_{0}}$ is related to the stiffness reduction consecutive to the first cycle and is determined as described in section 3.2.2. Therefore, relative loss of stiffness during fatigue can be written as:

$\left(\frac{\mathrm{E}}{\mathrm{E}_{0}}\right)_{\mathrm{N}}=\left(1+\mathrm{a}\left(\sigma-\sigma^{\mathrm{S}}\right)\right)^{*}\left\lfloor\frac{\mathrm{N}}{\mathrm{N}_{\mathrm{s}}}\right\rfloor^{\mathrm{B}}$

Arising from the introduction of equation (12) into equation (10), an analytical expression of the evolution of the local damage rate $\frac{d}{d_{c}}$ under fatigue loading is derived:

$\frac{\mathrm{d}}{\mathrm{d}_{\mathrm{c}}}=\alpha_{\mathrm{i}}\left[\left(1+\mathrm{a}_{\mathrm{i}}\left(\sigma-\sigma_{\mathrm{i}}^{\mathrm{S}}\right)\right)^{*}\left[\frac{\mathrm{N}}{\mathrm{N}_{\mathrm{s}}}\right]^{\mathrm{B}_{\mathrm{i}}}\right]^{2}+\beta_{\mathrm{i}}\left[\left(1+\mathrm{a}_{\mathrm{i}}\left(\sigma-\sigma_{\mathrm{i}}^{\mathrm{S}}\right)\right)^{*}\left[\frac{\mathrm{N}}{\mathrm{N}_{\mathrm{s}}}\right)^{\mathrm{B}_{\mathrm{i}}}\right]+\gamma_{\mathrm{i}}$

This expression gives the evolution of the local damage state $\frac{d}{d_{c}}$, for each considered number of cycle, $\mathrm{N}$, applied at the considered maximum stress, $\sigma$. As defined above, macroscopic failure occurs when $\frac{\mathrm{d}}{\mathrm{d}_{\mathrm{c}}}=1$ and $\mathrm{N}=\mathrm{N}_{\mathrm{r}}$, where $\mathrm{N}_{\mathrm{r}}$ is the number of cycle to failure.

The resolution of equation (13) leads to the expression of the number of cycles to failure as a function of the applied stress:

$\mathrm{N}_{\mathrm{r}}=\mathrm{N}_{\mathrm{s}} *\left[\frac{\mathrm{G}_{\mathrm{i}}}{\left(1+\mathrm{a}_{\mathrm{i}}\left(\sigma-\sigma_{\mathrm{i}}^{\mathrm{S}}\right)\right)}\right]^{\frac{1}{\mathrm{~B}_{\mathrm{i}}}}$

with $\mathrm{G}_{\mathrm{i}}=\frac{-\beta_{\mathrm{i}}-\sqrt{\beta_{\mathrm{i}}^{2}-4 \alpha_{\mathrm{i}}\left(\gamma_{\mathrm{i}}-1\right)}}{2 \alpha_{\mathrm{i}}}$

This expression allows plotting SN curve for any microstructure configurations. Damage is indirectly taken into account though the micromechanical parameters, $\alpha_{\mathrm{i}}, \beta_{\mathrm{i}}$ and $\gamma_{\mathrm{i}}$. The initial damage is conditioned by two parameters; $a_{i}$ and $\sigma_{i}^{\mathrm{S}}$ and fatigue kinetics of damage depends on the parameter $\mathrm{B}_{\mathrm{i}}$. The five first parameters are directly derived from the micromechanical model as a function of the considered microstructure. $B_{i}$ can be obtained by measuring the slope of the loss of stiffness under fatigue loading. Practically, one can perform a fatigue test at a maximal stress equal to half of the ultimate stress. While the experimental data expected from this test is the $B_{i}$ parameter (corresponding to the loss of stiffness slope), it is not needed to complete the test until final failure. Note that this test should be repeated several times for scattering materials such as SMC composites.

The proposed procedure was applied for three different microstructure configurations: $\mathrm{RO}, \mathrm{HO}-0^{\circ}$ and $\mathrm{HO}-90^{\circ}$. A micromechanical tensile modeling was performed for each configuration in order to identify $\alpha_{\mathrm{i}}, \beta_{\mathrm{i}}, \gamma_{\mathrm{i}}, \mathrm{a}_{\mathrm{i}}, \sigma_{\mathrm{i}}^{\mathrm{S}}$. $B_{i}$ was identified from a fatigue test as described above. For the sake of validation of our methodology, a fatigue campaign was completed for the three considered microstructures. Finally, comparison of simulated Wohler curves to experimental results for RO, $\mathrm{HO}-0^{\circ}$ and $\mathrm{HO}-90^{\circ}$ samples is illustrated in Fig. 7. One can note a very good agreement which demonstrates the efficiency of the proposed

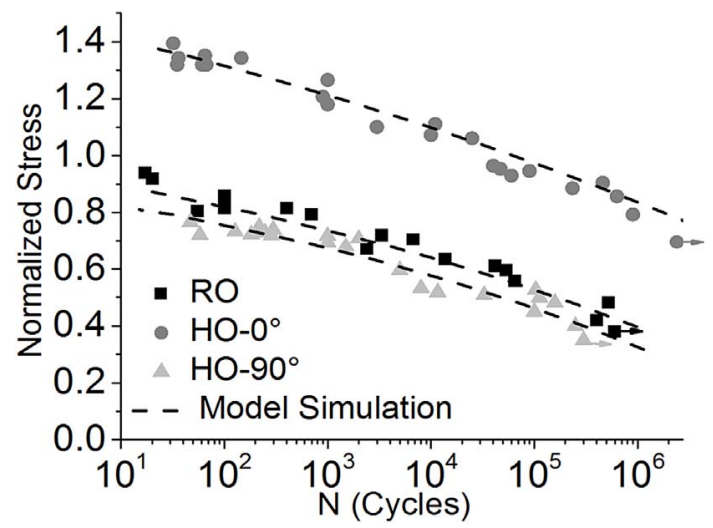

Fig. 7. Model simulation. 
methodology.

\section{Highlights and actual limitations of the approach}

Because of the character of novelty of the proposed approach, it is necessary to discuss about its potential and actual limitations. The main assumption is that there is a link between monotonic and fatigue mechanical behavior. Some authors also recently highlighted a relation between fatigue limit and quasi-static damage threshold [38]. Indeed, experimental evidence shows that the same damage and failure mechanisms are observed for the two types of loading. Therefore, the relationship between the crack density and the loss in stiffness can be determined in the case of a simple monotonic tensile test and be used in the case of tensile fatigue loading.

It has been demonstrated that this approach is efficiency in the case of constant tensile loading. On the other hand, real structures are submitted to variable amplitude loading. However, under tensile loading, it has been shown that the macroscopic fatigue damage rate (characterized by B) can be considered as independent of the amplitude in the case of standard SMC composites. Therefore, it can be assumed that each microscopic damage state can be represented by an overall local damage value (here $\frac{d}{d_{c}}$ ) independently of the tensile history which has led to this specific damage state. Thus, the increment of local damage $\left(\frac{\Delta d}{d c}\right)$ is calculated at the local scale as a function of the actual damaged microstructure for the actual macroscopic stress ( $\sigma$ in equation (13)) independently of the tensile loading history. A further paper will illustrate the efficiency of this approach even for variable amplitude fatigue loading. Several variable amplitude cases will be illustrated for validation of the approach in the case of tensile fatigue (to be submitted to Composites Part B).

Many other fatigue parameters influences should be evaluated in order to improve the efficiency of our approach. For example, the effect of compression and shear stresses and more generally the effect of complex loading and that of the mean stress should be studied. Actually, the model only takes into account the effect of the maximum applied stress. In a first approximation, this assumption can be considered valuable since the damage threshold under compression is $50 \%$ higher than tensile damage threshold. In the case of shear stress, the maximum absolute value must be considered. For each of these cases, it should be also verified that local damage scenario are similar in monotonic and fatigue loading. Moreover, even if the micromechanical approach allows the identification of $a_{i}, \sigma_{i}^{S}, \alpha_{i}, \beta_{i}, \gamma_{i}$, the macroscopic damage rate, $B_{i}$, must be evaluated experimentally together with its sensitivity to amplitude for any fatigue loading scheme.

One should also consider the limitation of the approach in the case of thermoplastic matrix. Indeed, the model should be improved in order to take into account the effect of the local plastic deformation accumulated under fatigue loading.

\section{Conclusion and perspectives}

In this paper, we propose a new hybrid approach allowing fast Wöhler curves prediction for SMC composite materials as a function of the considered microstructure. As fatigue tests require long and costly experimental campaigns, it is of first importance to speed the fatigue life evaluation which should be determined several times in the design phases which involve several compounding and processing steps.

On one hand, this approach can be qualified as a "stiffness based fatigue life prediction model". On the other hand, the model is based on a multi-scale description of damage. A micromechanical model is used and integrates, at the local scale, the main damage phenomenon observed in the case of SMC submitted to monotonic or fatigue loading: fiber-matrix interface failure. This pragmatic approach supposes that there is an equation of state which remains valid for both monotonic and fatigue loading. In other words, we consider that for a given residual stiffness state, the global quantity of local damage cumulated in the material is equivalent for tensile or fatigue loading. In light of this hypothesis, the equation of state can be established using a micromechanical modeling whose parameters can be identified in the case of a simple tensile test and be used in the case of fatigue loading. Moreover, final failure is assumed to always occur when a critical amount of local damage is reached. The latter is also identified by the micromechanical model by calculating the amount of local damage reached at the measured tensile failure. It has been shown that, in the case of tensile loading, a direct relation between the local damage rate and the number of applied cycles can be derived. The resolution of this equation for the identified critical amount of local damage allows plotting the SN curve for the considered microstructure.

The predictions of our hybrid approach are validated with experimental results in the case of constant tensile fatigue loading. Indeed, the $\mathrm{SN}$ curves are in very good agreement for three different microstructure configurations: $\mathrm{RO}, \mathrm{HO}=0^{\circ}$ and $\mathrm{HO}=90^{\circ}$.

The originality of this approach lies in using local damage state as variable in the fatigue behavior description. The use of a micromechanical approach which integrates microstructure as an input data is a major asset of this fast prediction method. Moreover, the model was implemented in industrial software and used as a damage approach for composite system's reliability in the case of the new Peugeot 3008 tailgate reinforced by SMC composite material [37]. Application of this approach under a thermo mechanical fatigue loading required by Peugeot has been also validated [37]. However, it should be noticed that the presented approach is relevant only for elastic damageable composite materials such as SMC. Ongoing work concerns the development of this approach for thermoplastic matrix composites for which matrix plasticity should be coupled to damage at the local scale. An evaluation of the approach should be performed in the case of complex loading (at least two dimensional loading for industrial applications) and variable fatigue loading. In the same way, in order to generalize the approach for other materials, one should also consider other local damage mechanisms such as fiber breakage or matrix micro-cracking which can be placed in competition with fiber-matrix interface failure.

\section{References}

[1] Degrieck J, Van Paepegem W. Fatigue damage modelling of fibre-reinforced composite materials. Rev Appl Mech Rev 2001;54(4):279-300.

[2] Simoes T, Octavio C, Valença J, Costa H, Dias-da-Costa D, Júlio E. Influence of concrete strength and steel fibre geometry on the fibre/matrix interface. Compos Part B 2017;122:156-64.

[3] Rolland H, Saintier N, Wilson P, Merzeau J, Robert G. In situ X-ray tomography investigation on damage mechanisms in short glass fibre reinforced thermoplastics: effects of fibre orientation and relative humidity. Compos Part B 2017;109:170-86.

[4] Mortazavian S, Fatemi A. Effects of fiber orientation and anisotropy on tensile strength and elastic modulus of short fiber reinforced polymer composites. Compos Part B 2015;72:116-29.

[5] Roundi W, El Mahi A, El Gharad A, Rebière JL. Experimental and numerical investigation of the effects of stacking sequence and stress ratio on fatigue damage of glass/epoxy composites. Compos Part B 2017;109:64-71.

[6] Barnard PM, Butler RJ, Curtis PT. Fatigue scatter of UO glass epoxy, a fact or fiction? Marshall IH, editor. Composite structures, vol. 3. 1985.

[7] Shirinbayan M, Fitoussi J, Meraghni F, Surowiec B, Bocquet M, Tcharkhtchi A. High strain rate visco-damageable behavior of Advanced Sheet Molding Compound (ASMC) under tension. Compos Part B Eng 2015;3670(82):30-41.

[8] Arif MF, Saintier N, Meraghni F, Fitoussi J, Chemisky Y, Robert G. Multiscale fatigue damage characterization in short glass fiber reinforced polyamide-66. Compos Part B 2014;61:55-65.

[9] Bellenger V, Tcharkhtchi A, Castaing P. Thermal and mechanical fatigue of a PA66/ glass fibers composite material. Int J Fatigue 2006;28(10):1348-52.

[10] Khan R, Alderliesten R, Badshah S, Benedictus R. Effect of stress ratio or mean stress on fatigue delamination growth in composites: critical review. Compos Struct 2015;124:214-27.

[11] Andersons J, Hojob M, Ochiaic S. Empirical model for stress ratio effect on fatigue delamination growth rate in composite laminates. Int J Fatigue 2004;26(6):597-604.

[12] Kotik H, Perez Ipiña J. Frequency effect in short-beam shear fatigue of a glass fiber reinforced polyester composite. Int J Fatigue 2016;90:116-24.

[13] Eftekhari M, Fatemi A. On the strengthening effect of increasing cycling frequency on fatigue behavior of some polymers and their composites. Exp Model Int J Fatigue 2016;87:153-66. 
[14] Passipoularidis V, Brondsted P. Fatigue evaluation algorithms: review. Roskilde: Danmarks Tekniske Universitet, Risø Nationallaboratoriet for Bæredygtig Energi; 2010. (Denmark. Forskningscenter Risoe. Risoe-R; No. 1740(EN)).

[15] Palumbo D, De Finis R, Giuseppe Demelio P, Galiettiet U. A new rapid thermo graphic method to assess the fatigue limit in GFRP composites. Compos Part B 2016;103:60-7.

[16] Rajaneesh A, Satrio W, Chai GB, Sridhar I. Long-term life prediction of woven CFRP laminates under three point flexural fatigue. Compos Part B 2016;91:539-47.

[17] Jegou L, Marco Y, Le Saux V, Calloch S. Fast prediction of the Wöhler curve from heat build-up measurements on Short Fiber Reinforced Plastic. Int J Fatigue 2013;47:259-67.

[18] Marco Y, Huneau B, Masquelier I, Le Saux V, Charrier P. Prediction of fatigue properties of natural rubber based on the descriptions of the cracks population and of the dissipated energy. Polym Test 2017;59:67-74.

[19] Serrano Abello L, Marco Y, Le Saux V, Robert G, Charrier P. Fast prediction of the fatigue behavior of short fiber reinforced thermoplastics from heat build-up measurements. Procedia Eng 2013;66:737-45.

[20] Masquelier I, Marco Y, Le Sauxa V, Callocha S, Charrier P. Thermal measurements on elastomeric materials: from the characterization of the dissipation gradients to the prediction of the fatigue properties. Procedia Eng 2013;66:661-8.

[21] Marco Y, Masquelier I, Le Saux V, Charrier P. Fast prediction of the Wohler curve from thermal measurements for a wide range of NR and SBR. Rubber Chem Technol September 2017;90(3):487-507.

[22] Shirinbayan M, Fitoussi J, Meraghni F, Surowiec B, Laribi M, Tcharkhtchi A. Coupled effect of loading frequency and amplitude on the fatigue behavior of advanced sheet molding compound (A-SMC). J Reinf Plastics Compos 2017;36(4):271-82.

[23] Jain A, M Veas J, Straesser S, Van Paepegem W, Verpoest I, Lomov VS. The Master SN curve approach - A hybrid multi-scale fatigue simulation of short fiber reinforced composites. Compos Part A December 2016;91(Part 2):510-8.

[24] Jain A, Van Paepegem W, Verpoest I, Lomov VS. A feasibility study of the Master SN curve approach for short fiber reinforced composites. Int J Fatigue 2016;91:264-74.

[25] Tamboura S, Sidhom H, Baptiste D. Evaluation de la tenue en fatigue du composite SMC R42. Matériaux Tech 2001;3-4:p3-11.

[26] Jendli Z, Meraghni F, Fitoussi J, Baptiste D. Micromechanical analysis of strain rate effect on damage evolution in sheet molding compound composites. Compos Part A Appl Sci Manufact 2004;35:779-85.

[27] Jendli Z, Meraghni F, Fitoussi J, Baptiste D. Multi-scales modelling of dynamic behaviour for discontinuous fibre SMC composites. Comp. Sci Technol 2009;69:97-103.

[28] Fitoussi J, Guo G, Baptiste D. Determination of a tridimentional failure criterion at the fiber-matrix interface of an organic matrix/discontinuous reinforcement composite. Compos Sci Technol 1996;56:755-60.

[29] Shirinbayan M, Fitoussi J, Meraghni F, Surowiec B, Bocquet M, Tcharkhtchi A. High strain rate visco-damageable behavior of Advanced Sheet Molding Compound (ASMC) under tension. Compos Part B Eng 2015;3670(82):30-41.

[30] Shirinbayan M, Fitoussi J, Abbasnezhad N, Meraghni F, Surowiec B, Tcharkhtchi A. Mechanical characterization of a Low Density Sheet Molding Compound (LD-SMC): Multi-scale damage analysis and strain rate effect. Compos Part B 2017;131:8-20.

[31] Krause D. Physically based micromechanical approach to model damage initiation and evolution of fiber reinforced polymers under fatigue loading conditions. Compos Part B 2016;87. 176-195A.

[32] Oskay, Numerical Modelling of Failure in Advanced Composite Materials. A volume in Woodhead Publishing Series in Composites Science and Engineering 2015, pp 351-375.

[33] Mori T, Tanaka K. Average stress in matrix and average elastic energy of materials with misfitting inclusions. Acta Metall 1973;21:571-4.

[34] Benveniste Y. A new approach to the application of Mori-Tanaka's theory. Mech Mater 1987;6:147-57.

[35] Eshelby JD. The elastic field outside an ellipsoidal inclusion. Proc Roy Soc Lond Ser A 1959;252:561-9.

[36] Fitoussi J, Guo G, Baptiste D. A statistical micromechanical model of anisotropic damage for S.M.C. composites. Compos Sci Technol 1998;58(5):759-63.

[37] Tiebi R, Laribi MA, Fitoussi J. Damage approach for composite system's reliability: application on SMC component in automotive industry. SIA (Société des Ingénieurs de l'Automobile) Conference: La simulation numérique au cœur de l'innovation automobile. France: Estaca Paris Sacley; March 2017.

[38] Lomov SV, Carvelli V, Jain A. Fatigue limit: is there a link to quasi-static damage? Conference paper, vol. 21. ICCM; August 2017. 